\title{
The Impact of Modern Technological Tools on Students Writing Skills in English as a Second Language*
}

\author{
Amani M. Alhusban \\ University of Jordan, Amman, Jordan
}

\begin{abstract}
While technology has certainly advanced itself and become fundamental aspect of life today, there are several harmful effects that negatively influence students writing in the classroom. Technology quickens and simplifies tasks for students, yet it has ingrained in them and an attitude that they do not have to put effort into anything they write. In this study, the relationship of new technologies to writing and its implications is reviewed. A case study and existing literature on the effects of electronic and communicative devices on English writing among college students are evaluated. The study reveals that due to the constant exposure to shortened forms of words and programs that essentially do the work for the students, they are now having difficulty distinguishing between informal and formal writing. As a result, teachers are currently observing dramatic increase in the informal language that is "creeping" itself into formal writing pieces, and consequently, causing a drastic decline in student's writing overall.
\end{abstract}

Keywords: writing, communication, technology, impact, netspeak

\section{Introduction}

As writing is a key factor in obtaining success in college and career, it is important for students to be able to write independent of all assistance and technological methods. Writing skills, such as writing mechanics, writing strategies, writing in a way that communicates idea clearly and concisely, constructing a reasoned argument, and organizing evidence and ideas are increasingly becoming important to be attained. If students do not know how to write effectively with sophistication and precision, they may not be considered or accepted into colleges or universities. Moreover, these individuals may not even stand a chance against other, more qualified individuals when competing for positions in the job market.

In order to graduate from college and university, and compete in a highly competitive global economy, students need to achieve writing proficiency. Therefore, it is vital that students are introduced to formal writing and are provided with a chance to produce professional formal reports. In fact, the work force demands that individuals write with grammatical precision and be able to search deeply into a topic and provide an argument by writing logically and coherently supported by evidence.

Unfortunately, educators have seen a drastic decline in students' writing capabilities as a result of new technological advancements. The current problem lies in technology and students' mentalities, and due to technology, students do not always see the importance of truly understanding the English language and

\footnotetext{
${ }^{*}$ The paper was presented on ERPA International Congresses on Education 2015, ERPA Congresses 2015, 4-7 June 2015. Amani M. Alhusban, M.A. in English Language and Literature/Language, University of Jordan.
} 
grammatically correct written expression. As a result of new technological advances, students want to "click to find" without actually understanding the complexity involved in writing (Purcell, Buchanan, \& Friedich, 2013). With the spell check access on Microsoft Word and Microsoft PowerPoint, students often take shortcuts, making it clear that spelling, grammar, and sentence structure are of no importance to learn since technology does the job for them. However, if students do not understand certain, crucial aspects of the writing process, these technological tools will cause them damage and lead to misunderstandings (Purcell et al., 2013).

The more students rely on technology for writing assignments, the greater the decline in their ability to deal with their writing skills and tasks. Students are losing the ability to express complete thoughts and cannot think on their own. In general, technology is hiding students' misunderstandings and interfering with their learning.

As a result, students are not able to critically think and analyze evidence, synthesize information, write evidence-based claims, and recognize appropriate grammatical and structural errors (Rothman, 2012).

In addition to computer programs, text messaging is another major technological advancement that is deterring students from successfully completing formal written tasks. With the significant increase in the amount of texting, it has been proven that texting could "heighten the tendency among students to adopt non-standard uses and contracted forms of English words in their class work" (Dansieh, 2011, p. 222).

Texting produces an abbreviated mind set in students, often enabling them to write with little detail and represent words by replacing them with shorter, less sophisticated words. Dansieh (2011, p. 224) elaborated on this issue by providing readers with examples of words that are shortened through the use of symbols that sound like the syllable of specific words. This action only produces misspelled words and words new words that do not currently exist in the English language. Examples of these words and phrases, that are used when texting are "4U" for "for you," "B4" for "before," "LOL" for "laughing out loud," "shud" for "should," and "gr8" for "great" (Daisieh, 2011, p. 224).

Furthermore, as new and more advanced forms of technology continue to evolve in society today, cyber writing is becoming more dominant by image and graphics than texts in online communication (Bromley, 2006). As a result, getting distracted by modifying fonts, colors, or images prevents students from delving deeply into writing pieces, expressing more profound ideas, and revising their writing to create a more refined piece (Omar $\&$ Miah, 2012).

Writing should represent hard work that comes with reward and confidence after utilizing critical thinking skills and cognitive effort. However, the ease of access on the Internet and the copy-past options offered by advanced tools allow for plagiarism (Omar \& Miah, 2012; Bromley, 2010).

An opposing school of thought, led by Crystal (2008), argued that advanced technologies especially texting is not harmful to students reading and writing skills; rather it enhances them. In his book Txtng: The Gr8 Db8 (a logogram which stands for Texting: The Great Debate), Crystal (2008) put forward six main points to support his positive view towards texting. These are: (1) typically, less than $10 \%$ of the words are abbreviated in text message; (2) abbreviating is not a new language rather it has been present for many decades; (3) both children and adults use SMS language; adults being more likely to do so; (4) students do not habitually use abbreviation in their homework and examinations; (5) texting cannot be a cause of bad spelling since people need to know how to spell before texting; and (6) since texting provides more opportunities for people to read and write, sending text messages improves students' literacy.

In spite of the apparently huge volumes of work on the subject of technology and first language development, the literature seems not to have enough research on the phenomenon as it pertains in second 
language learning and requires profound investigation. This study investigates the implications of modern technologies on writing practices of college students learning English as their second language.

\section{Rational for the Study}

The 21 st century students are not sustaining the mental energy that is necessary to write well and do not see the value in writing well. Therefore, numerous English teachers, whose curriculum thrives on written expressions, are currently facing a real and valid problem. Since technology has implanted this belief in students that they can always take shortcuts without thoroughly comprehending the writing process, students fail to see the importance of learning the correct way of writing.

If students are to succeed in college or in career settings, and be valuable contributors in the academic and professional world, it is crucial that they are well equipped with sophisticated writing skills. Therefore, in this current generation, it is the wrong time for college students' writing to be worse than any other generation. We cannot stop technological advances from continuing to rise, but we can ensure that our students attain the formal writing skills that are necessary for successful achievement in the academic and professional areas of society.

Based on the results of such descriptive studies of students' performances in writing assignments, teachers must utilize the writing standards as a guide in generating productive lessons that outline the differences between informal and formal writing, and further support formal writing with strategies that reflect the importance and implication of the process.

\section{Methodology and Data Collection}

As a descriptive case study, both quantitative and qualitative approaches to the collection and analysis of data were adopted. To look at writing skills, two types of the students' writing skills were collected and compared. These are the free writing and formal writing assignments.

Students from whom the sample is collected belong to college students. This group of students is believed to be representative of college students aged between 18-22 years old. An age that is highly believed to be addicted to modern technologies, such as their smart phones or iPads, as well as being addicted to social media websites and mobile phones application.

One hundred writing assignments were collected. Both free and formal writing students' assignments were checked and compared concerning their contents of grammar, vocabulary, spelling, punctuation, and style. The numbers of specific errors in the sample were contrasted, and frequencies and means were used as measurement of possible differences between formal and informal writing styles, as being influenced by the students' constant use of modern and sophisticate technologies.

\section{Findings and Discussion}

The main characteristics of both types of writing from students assignments are as summarized in Table 1 based on their frequency. As it indicated in Table 1, correct grammar, spelling, punctuation, and capitalization, which are conventional characteristics of normal written language, were not acceptable in the students' writings. Moreover, some students used instant messages (IM) language in their free writing as well as using chat emoticons. Sloppy written body, improper capitalization, and other deviations found in the free writing analyzed work refer to the fact that the language used by the students is highly influenced by modern technologies, especially by recent smart phones and the trend of IMs via the new-fangled social media applications. 
Table 1

Frequency of Writing Mistakes

\begin{tabular}{lcc}
\hline Categories & Frequency "free writing” & Frequency "formal writing" \\
\hline Poor grammar & 26 & 13 \\
Misspelled words & 29 & 11 \\
Improper capitalization & 8 & 0 \\
Irrelevant punctuation & 20 & 15 \\
Sloppy written body & 30 & 10 \\
Use abbreviations \& acronyms & 33 & 5 \\
Rambling & 11 & 9 \\
Use of netspeak & 34 & 3 \\
Use of graphics & 18 & 1 \\
Plagiarism & 3 & 6
\end{tabular}

As for the formal writing, it seems that this language register of netspeak or shortened "textspeak" (i.e., abbreviations as used in mobile phone communication, such as b4 = before) has started to be used in appropriate contexts of formal writing.

Based on these finding and related research, many more concerns have been raised as to the negative impacts of these technologies in writing skills. A few of these concerns are reviewed briefly below:

\section{Standard Spelling and Punctuation}

The informal language register of netspeak has also encouraged poor written English. For example, the text of many Web pages is considerably shorter than printed text, using short sentences and paragraphs for ease of reading due to the constraints of screen size.

E-mail and short messaging service (SMS) are used for speed communication in which the occasional error may slip by. Students, who write with no capitalization and punctuation for the sake of brevity and convenience without thinking of academic consequences, risk being considered as lazy and not taken serious.

\section{Grammatical Syntactic Rules}

The content analysis of students formal and informal writing used in this study shows the development and the increase use of language short forms used in IM communication, which retain both written and spoken language characteristics.

Speech and writing can be described both in terms of the production and reception contexts. It is understandable that IM users make use of linguistic short-cuts applying the properties of both written and spoken language to the less formal language used in text messages, but the conventions of politeness and formality often remain necessary. It is worth emphasizing that the use or overuse of abbreviations, acronyms, linguistic short-cuts, capitalization, and punctuation should be based on the writing style and context.

Punctuation is often used in netspeak to convey meanings that cannot be provided by nonverbal cues, as would be used in face-to-face discourse (e.g., the use of "emoticons," such as $;$; to indicate smiling). There is a concern that this may transfer into formal written English and encourage grammatical and syntactic rules to be overlooked.

\section{More Graphical Rather Than Text}

A related concern of many educators is that online communication is dominated by graphics rather than texts and those students that use multimedia will get distracted from writing and instead waste a great amount 
of time on perfecting fonts, colors, or images. Giving much attention to the design can result in students paying little attention to texts and contexts.

\section{Absence of Proof Reading}

A further concern is that computer spell-checking, predictive-texting, and auto-correction applications are de-skilling for children, and that the speed of some electronic communication encourages spelling and typing mistakes to be overlooked.

\section{Reduction in Critical Thinking Abilities}

Another concern is the loss in critical thinking abilities due to the copy and paste options that these technologies often present. This has paved way for practices like plagiarism. Online plagiarism takes a variety of forms from the blatant and intentional (e.g., purchasing an essay online) to the accidental and ill-informed (e.g., quoting small amounts of online material without proper citation).

However, the Internet also provides instructors the opportunities to check for plagiarism, either informally through search engines or through special commercial antiplagiarism sites.

Plagiarism for second language learners is a complex and challenging issue, at the same time that they are encouraged to improve their language through modeling and copying the words of others, they are prohibited from doing so in certain instances. The new challenges of plagiarism in the online era can provide instructors a valuable opportunity to address this issue head on in the classroom, and thus help students advance their understanding of the nature of academic research and writing.

\section{Loose of Linearity and Sequencing}

Linearity and coherence are integral elements in traditional writing. Ideas are expressed in a logical and linear fashion which delivers a coherent narrative in large chunks of text, large chunks of text defeat the purpose of hypertext. Hypertext allows writers to present information loosely, rather than in a well-developed form.

\section{Conclusions}

It is evident that modern technological tools are redefining modern writing and writing skills. Students nowadays are "changing the nature of the English language" and relying on technology to "fix" all their writing errors (Bromley, 2010, p. 103). This trend has introduced new forms of language, for example, "netspeak," in which students use abbreviated words, combine numbers, letters, and symbols to stand for specific words, as well as neglecting the grammatical and syntactic rules of correct English.

Moreover, the nature of text messages transferred to students writing created a sense of laziness in students. Students benefit from "predicting text" options to save their time and energy. On the other hand, it lowers students' mental energy and decreases their persistence.

Students have become so accustomed to taking shortcuts and writing in small bites that they fail to see the purpose of writing, editing, revising, and re-writing, not to mention using correct grammar and appropriate sentence structure.

Within the context of the classroom, writing tasks with these challenging, yet valuable requirements need to happen now and more frequently than ever before. However, prior to completing formal written tasks and grasping the importance of formal writing, it is crucial that students thoroughly understand the difference between informal and formal writing, and are able to identify the contexts in which each is appropriate. Once, this crucial step is taken, students can practice the formal, advanced, and sophisticated writing skills that are 
expected in college and the work place, while simultaneously attaining a sense of inspiration and motivation to write well, and in turn, express confidence about the work that they possess.

\section{References}

Bromley, K. (2006). Technology and writing. In M. McKenna, L. D. Labbo, R. D. Kieffer, \& D. Reinking (Eds.), International handbook of literacy and technology, 2, 349-355.

Bromley, K. (2008). The future of writing. In M. Foote, F. Falk-Ross, S. Szabo, \& M. B. Sampson (Eds.), College reading association 29th yearbook. Navigating the literacy waters: Research, praxis \& advocacy (pp. 2-10). Commerce, T.X.: Texas A \& M University.

Bromley, K. (2010). Picture a world without pens, pencils, and paper: The unanticipated future of reading and writing. Journal of College Reading and Learning, 41(1), 97-108.

Crystal, D. (2008). Txtng: The gr8 $d b 8$. Oxford: Oxford University Press.

Dansieh, S. (2011). SMS texting and its potential impacts on students' written communication skills. International Journal of English Linguistics, 1(2), 222-229.

Madden, D., \& Laurence, D. (1994). An examination of college writing skills: Have they deteriorated? Education Resources Information Center. Retrieved May 2, 2015, from http://files.eric.ed.gov/fulltext/ED364909.pdf

Omar, A., \& Miah, M. (2012). Impact of technology on teens' written language. International Journal of Advanced Trends in Computer Science and Engineering, 1(1). Retrieved from http://www.warse.ijatcse.current

Purcell, K., Buchanan, J., \& Friedrich, L. (2013, July). The impact of digital tools on student writing and how writing is taught in schools. National Writing Project. Pew Research Center. Retrieved May 1, 2015, from http://www.pewinternet.org/2013/07/ 16/the-impact-of-digital-tools-on-student-writing-and-how-writing-is-taught-in-schools/

Rothman, R. (2012). A common core of readiness. Educational Leadership: College, Careers, \& Citizenship, 69(7), $10-15$. 